\title{
Effect of Dentures on Palatal Rugae: An Investigation
}

\author{
Rajesh Akula ${ }^{1 *}$, H. P. Srinath ${ }^{2}$, Sohani Maroli³, Siva Kiran Babu Yarlagadda², \\ D. Uday Kiran Tej ${ }^{4}$ and Tishia Srinath ${ }^{5}$ \\ 'Department of Dental, Ex-Servicemen Contributory Health Scheme, Srikakulam - 532 410, \\ Andhra Pradhesh, India; rajeshakula1703@gmail.com \\ ${ }^{2}$ Department of Prosthodontics, St. Joseph Dental College, Eluru, Andhra Pradesh, \\ India; srinath_hp@yahoo.com, yarlagadda1428@gmail.com \\ ${ }^{3}$ Department of Dental Faculty, Mysore Medical College and Research Institute, \\ Mysore, India; sohani_m@yahoo.com \\ ${ }^{4}$ Department of Prosthodontics, Anil Neerukonda Institute of Dental Sciences, Visakhapatnam, \\ Andhra Pradesh, India; teja.dr1012@gmail.com \\ ${ }^{5}$ MBBS Under Graduate Student, SDM College of Medical Sciences and Hospital, \\ Dharwad, Karnataka, India; srinath_hp@yahoo.com
}

\begin{abstract}
Aim: The aim of this study is to evaluate the rugae pattern changes (rugae number, length, shape, direction, and unification) in completely edentulous patients treated with complete denture. Materials and Methods: A total of 100 subjects were selected for the study. The experimental group comprised 60 participants ( 30 males and 30 females) who had undergone complete denture treatment and the control group comprised 40 participants (20 males and 20 females) who were dentulous and patients with fixed partial denture treatment. Mucostatic maxillary alginate impressions were made for all the subjects, and casts were poured with gypsum. Patients were recalled at the regular intervals of 1,6, and 18 months after the treatment. During those recalls, the same impression procedure was made, and all the palatal rugaes were observed for number, length, shape, direction, and unifications under magnifying lens. Changes in the palatal rugae were statistically analyzed using the unpaired $t$-test. Results: A gradual decrease in the length was observed in primary, secondary, and fragmentary rugae for the experimental group after denture wearing (Group 1). Statistically, the change was significant $(P$ $<0.001)$ in primary rugae only. A slight change in rugae shape was also observed in the experimental group after 18 months period of denture wearing which is statistically insignificant $(P>0.05)$. Conclusions: Significant decrease in primary rugae length in complete denture wearers was due to sustained mechanical stress posed by the dentures on palatal rugae. The other parameters such as rugae number, direction, and unification remained constant throughout the study. Palatal rugae analysis may not be helpful for human identification in complete denture wearers. Nevertheless, palatal rugae may serve as an adjuvant to other techniques such as DNA analysis and finger prints in forensic investigations.
\end{abstract}

Keywords: Complete Denture, Palatal Rugae, Rugae Pattern

Article chronicle: Date of Submission: 13.04.2019; Date of Acceptance: 25.01.2020; Date of Publication: 24.04.2020

\section{Introduction}

Anatomists always have shown interest in the evolutionary development of the folds of tissue found in the roof of the human mouth-the palatine rugae. ${ }^{1}$ Winslow seems to have been the first to describe them and the earliest illustration of them probably is by Santorini. Palatal rugae, also called plicae palatine transversae and rugae palatina, refer to ridges on the anterior part of the palatal mucosa on each side of the median palatal raphae and behind the incisive papilla.

In Prosthodontics, rugae area plays an effective role; it is a secondary stress bearing area that resists anterior displacement of the denture; Also it is considered as a part of the primary denture supporting area because it is not affected by resorption. Sometimes, rugae area is covered

${ }^{*}$ Author for correspondence 
to provide indirect retention for free extended denture base and there were efforts to use palatal rugae as a guide in positioning the artificial maxillary anterior teeth. ${ }^{2-4}$ In orthodontic treatment, palatine rugae can be used as internal dental-cast reference points for quantification of tooth migration. ${ }^{1}$

The anatomical position of the rugae inside the mouth surrounded by cheeks, lips, tongue, buccal pad of fat, teeth and bone keeps them well-protected from trauma and high temperatures. Thus, they can be used reliably as a reference landmark during forensic identification. If palatal rugae are destroyed, they are reproduced exactly on the same site. ${ }^{5}$ Sometimes palatal rugae adjacent to the alveolar arch slightly change their position after tooth extraction. ${ }^{6}$ However, few events can contribute to changes in palatal rugae including extreme finger sucking in infancy and persistent pressure with orthodontic treatment or dentures. ${ }^{7,8}$ No previous studies have investigated the changes in palatal rugae after wearing dentures.

So, the aim of this study is to explore the changes occurring in the palatal rugae pattern after wearing complete denture.

\section{Aim}

To investigate the changes in palatal rugae pattern among the complete denture wearers.

\section{Objectives}

To evaluate the rugae pattern changes in edentulous patients treated with complete denture such as:
1. Number
2. Length
3. Shape
4. Direction and
5. Unification.

\section{Subjects and Methods}

This is a longitudinal study conducted at the department of Prosthodontics, St. Joseph Dental College and Hospital, Eluru. Ethical clearance was obtained from the Institutional Ethical Committee. A total of 100 subjects were selected for the study. The selected subjects were then divided into two groups:

\section{Group 1}

60 completely edentulous patients with equal gender distribution were included in the experimental group. In all these patients, mucostatic maxillary alginate impressions are made carefully, and casts are poured with gypsum at the following four sessions:

- $\mathrm{T}_{0}$-Before treatment

- $\mathrm{T}_{1}-1$ month after treatment

- $\mathrm{T}_{2}-6$ months after treatment

- $\mathrm{T}_{3}-18$ months after treatment.

All the palatal rugae are observed for number, length, shape, direction, and unifications under the magnifying lens at four different sessions.

The comparison essentially between rugae number, length, shape, direction, and unification is between $\mathrm{T}_{0}$ and $\mathrm{T}_{3}$. However, $\mathrm{T}_{1}$ and $\mathrm{T}_{2}$ are included to get additional information on the possible changes that may occur.

\section{Group-2}

The control group comprises 40 subjects (20 males and 20 females) who were dentulous and patients with fixed partial denture treatment. In all these patients, maxillary alginate impressions are made carefully, and casts are poured with gypsum at following four sessions:

- $\mathrm{T}_{0}$-Before treatment

- $\mathrm{T}_{1}-1$ month after treatment

- $\mathrm{T}_{2}-6$ months after treatment

- $\mathrm{T}_{3}-18$ months after treatment.

\section{Inclusion criteria}

All participants were free of systemic diseases, 45-79 years old, with no history of prosthesis wearing, free of congenital abnormalities, inflammation, and trauma related to palate.

\section{Materials}

\section{For examination of the patient [Figure 1]}

1. Electrically operated dental chair with illumination

2. Plain mouth mirror, No. 5

3. Straight probe

4. Tweezer

5. Disposable glass tumbler with water

6. Disposable sterile gloves 
7. Disposable mouth mask

8. Gauze piece and cotton rolls

9. Kidney tray

\section{For impression making [Figure 2]}

1. Edentulous perforated metallic stock trays for maxillary impressions: upper: no 1, 2, 3, 4. (sterilized after every use in autoclave)

2. One flexible rubber bowl

3. Curved stiff-bladed stainless steel mixing spatula

4. Algin-gum (Batch no. 130308-01)

5. Alginate powder-measuring scoop

6. Measuring jar

7. Kidney tray

8. Disposable sterile gloves

9. Disposable mouth mask.

\section{For obtaining the study casts}

1. One stiff rubber bowl

2. Straight stiff-bladed stainless steel-mixing spatula

3. Plaster knife

4. Water

5. Type III Gypsum product, dental stone (Orthokal)

6. Rubber base former

7. Mechanical vibrator.

\section{For the measurements on the study casts}

1. Graphite pencil $(0.3 \mathrm{~mm})$

2. Magnifying lens

3. Brass wire

4. Digital Vernier calipers.

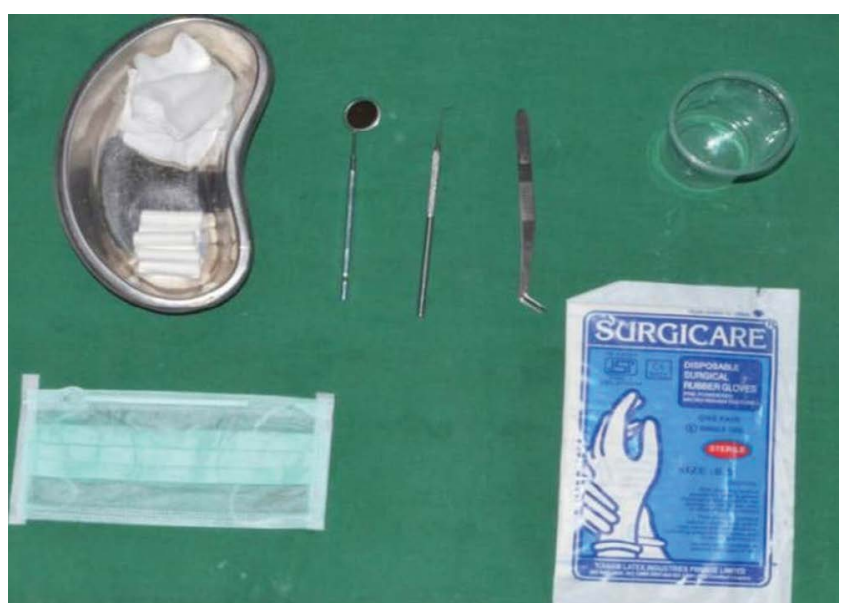

Figure 1: Armamentarium used for the examination of the patient

\section{Examination of the patient}

The patients were made to sit comfortably in the illuminated electrically operated dental chair. Complete oral examination of the patient was carried out according to the methods described in Kerr, Ash, Millard. ${ }^{9}$

The container of the alginate impression material was shaken vigorously each time before the use to ensure complete mixing of the contents. The powder scoop (provided by the manufacturer) was filled lightly without tapping. Only level scoops were employed for mixing. Two levels of the impression material were taken in the scoop and mixed with $40 \mathrm{ml}$ of water (using a measuring jar provided by the manufacturer), in a water/powder (W/P) ratio of $40 \mathrm{ml}: 15 \mathrm{~g}$ in a flexible rubber bowl with a mixing spatula. ${ }^{10} \mathrm{~A}$ vigorous figure of eight motion was used with the mix being swiped or stropped against the sides of the rubber mixing bowl with intermittent rotations $\left(180^{\circ}\right)$ of the spatula to press out air bubbles. The contents were mixed for $45 \mathrm{~s}$ to $1 \mathrm{~min}$ (mixing time of alginate material) till a smooth creamy mixture was obtained that did not drip off the spatula when it was raised from the bowl. The mix was immediately transferred to the impression tray for the insertion into the patient's mouth. The tray was held passively and motionless during the setting of impression material. After about $2 \mathrm{~min}$ (setting time of Alginate), the tray was separated quickly to avoid rocking and possible deformation of the fine areas of the impression. Excess material at the periphery was trimmed ${ }^{11}$ [Figure 3 and 4].

\section{Preparation of study cast}

Dental stone was mixed with water in a $\mathrm{W} / \mathrm{P}$ ratio of $28 \mathrm{ml}: 100$ g. ${ }^{10}$ The alginate impression was kept on the mechanical vibrator, and the mixed dental stone was

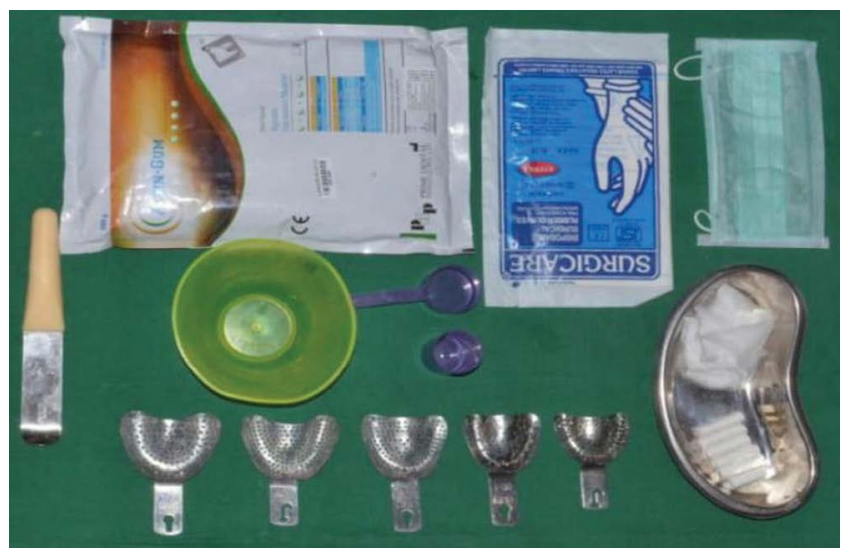

Figure 2: Armamentarium used for making impression 


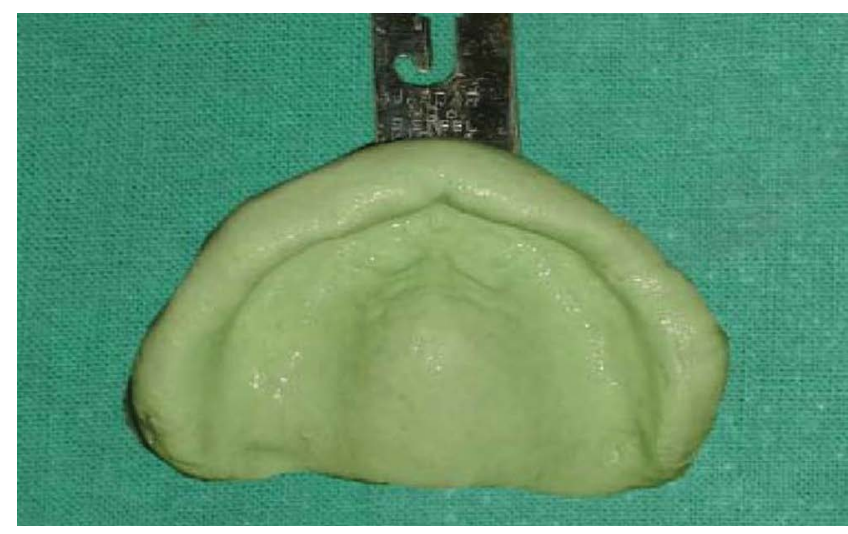

Figure 3: Mucostatic maxillary edentulous impression of Group 1 (Experimental group)

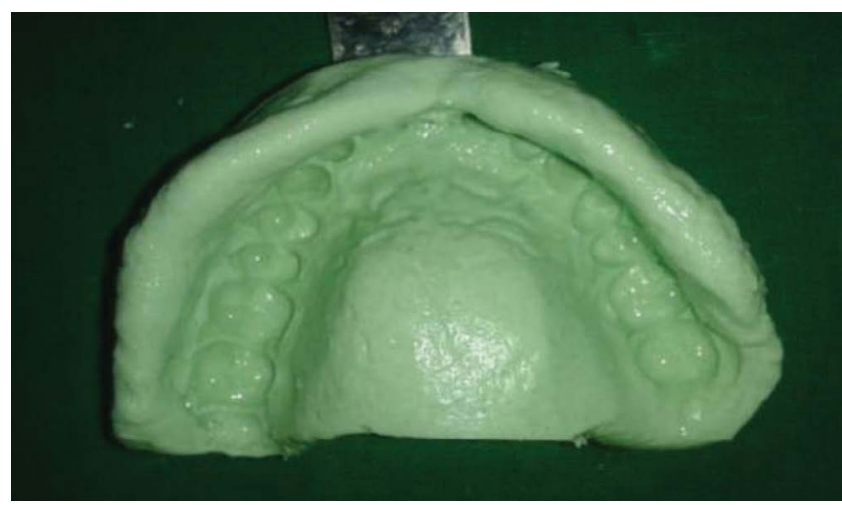

Figure 4: Mucostatic maxillary edentulous impression of Group-2 (Control group)

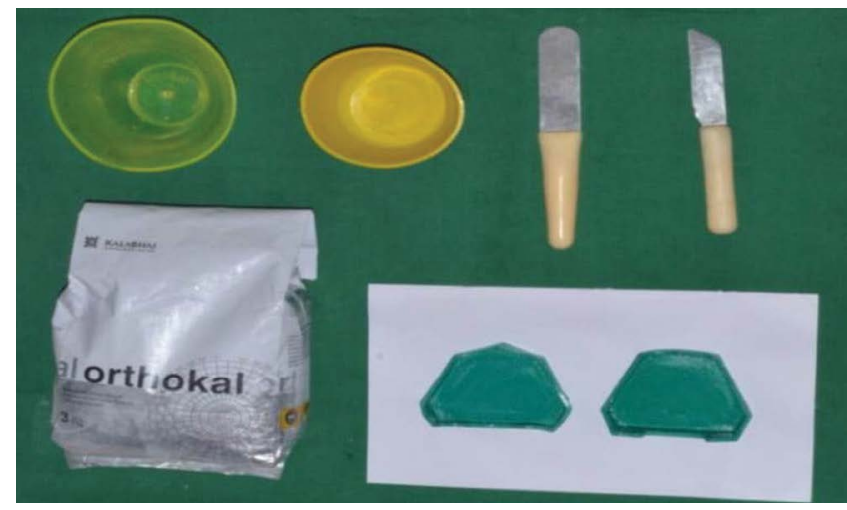

Figure 5: Armamentarium used for obtaining study cast

added to the impression in small increments to avoid air entrapment. The cast was separated from the impression after 60 min. ${ }^{12}$ Base for the study casts was made using the base former and dental stone [Figure 5]. Each cast was numbered for the easy identification.

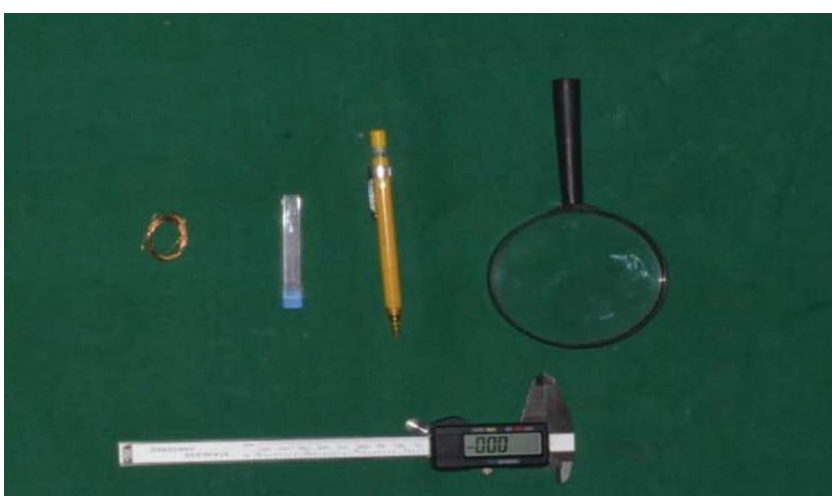

Figure 6: Armamentarium used for marking rugae on maxillary cast

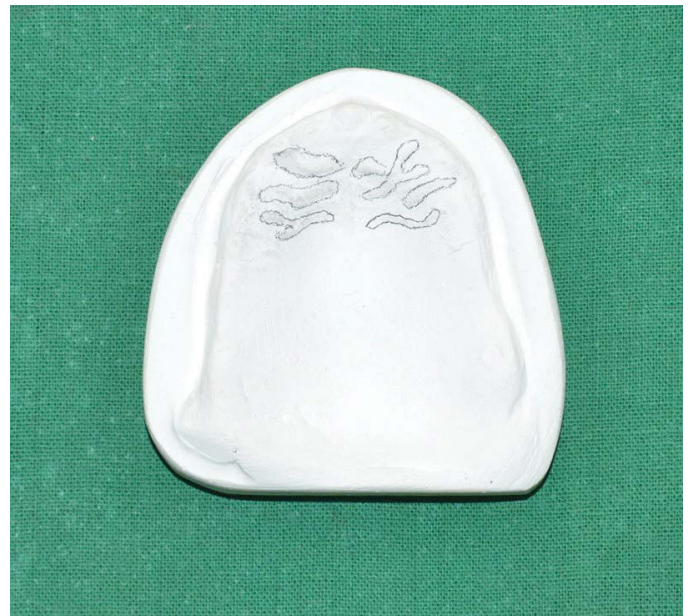

Figure 7: Marking rugae pattern on maxillary edentulous cast of Group-1 (Experimental group)

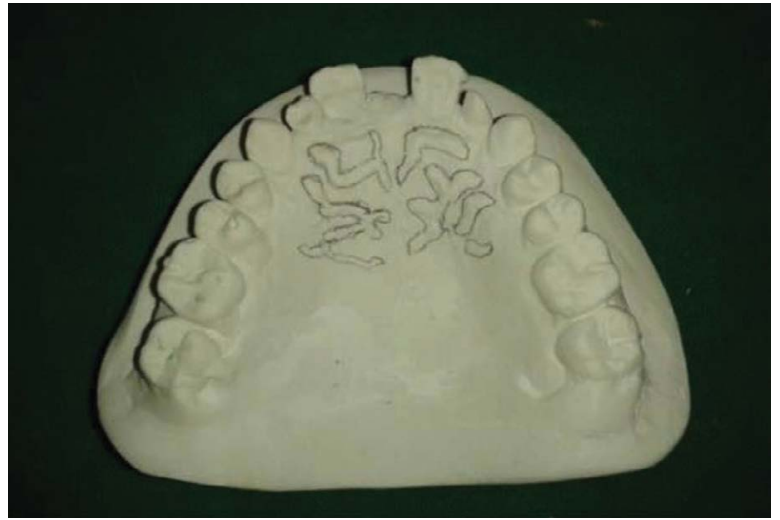

Figure 8: Marking rugae pattern on maxillary dentulous cast of Group-2 (Control group)

All the measurements were taken by a single observer. The observations were made in a quiet, well illuminated room [Figure 6]. The study casts were placed on a 


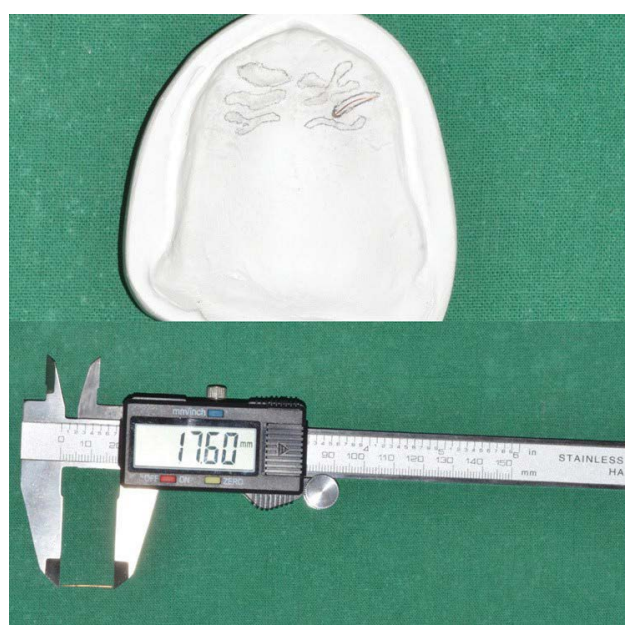

Figure 9: Measuring rugae length with brass wire and digital Vernier calipers

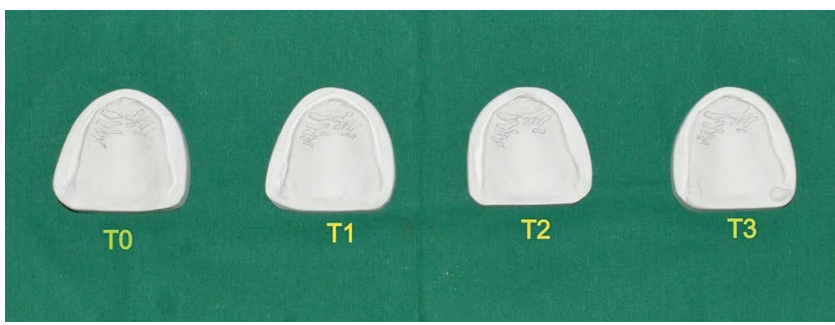

Figure 10: Marked rugae pattern on casts of Group-1 (experimental group) at four different sessions

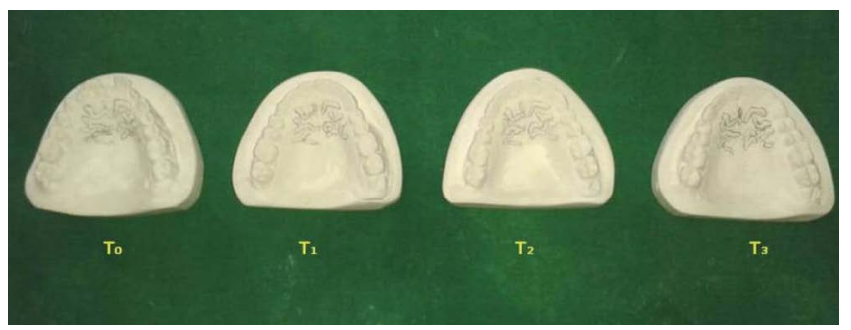

Figure 11: Marked rugae pattern on casts of Group-2 (control group) at four different sessions

horizontal base. The rugae were highlighted by a sharp 0.3 $\mathrm{mm}$ graphite pencil on the cast, and magnification lenses were used for the identification [Figures 7-11].

Interpretation of the rugae pattern in the casts was obtained by Thomas and Kotze classification. This classification is based on their length, shape, direction, and unification.

\section{Length analysis}

Using brass wire and digital calipers with an accuracy of $0.01 \mathrm{~mm}$, the maximum longitudinal length of all palatal rugae was calculated and founded. The rugae were classified based on their length as:

1. Primary- $>5 \mathrm{~mm}$

2. Secondary-3-5 mm

3. Fragmentary $-<3 \mathrm{~mm}$.

\section{Shape analysis}

The rugae were divided into four types based on their shape as:

1. Curved - They had crescent shape and curve gently

2. Wavy - If there was a slight curve at the origin or termination of curved rugae

3. Straight - They run directly from their origin to termination

4. Circular - Rugae that form a definite continuous ring were classified as circular.

\section{Direction analysis}

The direction of each main primary rugae was determined by measuring the angle between the line joining its origin and termination and a line perpendicular to the Median palatal raphae. Based on the direction, rugae were classified as:

1. Forward - directed rugae were associated with positive angles

2. Backward - directed rugae with negative angles

3. Perpendicular rugae with angles of zero.

\section{Unification analysis}

Unification occurs when two rugae are joined at their origin or termination.

1. Diverging: if two rugae had the same origin from the midline but immediately branched

2. Converging: rugae with different origin from midline, but which joined on their lateral portions.

The data thus obtained were recorded in a printed proforma, especially tailored to the objectives of this study. A written informed consent was obtained from the subjects participating in the study, and photographs were also taken. The data were analyzed regarding the number, length, shape, direction, and unification of the palatal rugae.

In this study, complete dentures were constructed for all patients. Special trays were prepared for each patient. 
Border molding was done with low-fusing modeling compound, and the corrective impressions were made with zinc oxide eugenol. Special care was taken to avoid pressure. Acrylic resin denture bases and cusp teeth were used.

\section{Statistical analysis}

All the details from each dental model were documented in data chart and analyzed for descriptive statistics. The collected data were further analyzed using Paired $t$-test to detect any significant effect of complete denture on palatal rugae pattern in the experimental group and compared with control group. In addition, unpaired $t$-test was done for gender differentiation. Statistical analysis was performed using the SPSS software version 20. (IBM Inc., Chicago, Ill., USA). The $P$ values were calculated under the predetermined level of significance of 0.05 at the confidence level of $95 \%$.

\section{Results}

\section{Age and sex distribution of study population}

The study population included a total of 100 patients who had undergone treatment in the department of Prosthodontics, St. Joseph Dental College and Hospital, Eluru [Table 1].

Table 1. Age and sex distribution of the study population

\begin{tabular}{llcc}
\hline Groups & Sex & Age (years) & $n$ \\
\hline (Group 1) & Male & $45-79$ & 30 \\
& Female & & 30 \\
(Group 2) & Male & & 20 \\
& Female & & 20 \\
\hline
\end{tabular}

In this study rugae pattern were observed in both Group 1 and Group 2 patients at four different sessions ( $\mathrm{T}_{0}$, $\mathrm{T}_{1}, \mathrm{~T}_{2}$, and $\mathrm{T}_{3}$ ). The comparison between rugae number, length, shape, direction, and unification was essentially between $T_{0}$ and $T_{3}$. However, $T_{1}$ and $T_{2}$ are included in the tables to get additional information on possible changes that may occur. These results are compared with the control group to unclear the age changes related to palatal rugae.

\section{Effect of denture on Rugae number}

On wearing of denture, the rugae number remained constant throughout the period of study in both Group 1 and 2 populations. Therefore, $t$-value and $P$ value cannot be computed [Tables 2 and 3 ].

\section{Effect of denture on rugae length}

The length of primary, secondary, and fragmentary rugae decreased gradually on wearing denture at each time intervals, on the right or left side of the palate among the males and females in Group 1 patients. On comparison of rugae length at the time of denture insertion $\left(\mathrm{T}_{0}\right)$ and 18 months after insertion $\left(\mathrm{T}_{3}\right)$, primary rugae length decrease was statistically significant $(P<0.001)$. Whereas, in case of secondary and fragmentary rugae, the decrease in length was statistically not significant [Table 4]. As shown in Table 5, the rugae length (primary, secondary and fragmentary) of Group 2 patients remains unchanged in $\mathrm{T}_{1} \mathrm{~T}_{2}$, and $\mathrm{T}_{3}$ sessions.

\section{Effect of denture on rugae shape}

As shown in Table 6, at a time interval of $\mathrm{T}_{4}(18$ months after insertion) slight decrease in the number of wavy-shaped rugae and slight increase in curved rugae on either sides of palate among both genders in Group 1 patients was observed, but it is statistically insignificant. Whereas in Group 2 patients, there was no change in the rugae shapes throughout the period of study [Table 7].

\section{Effect of denture on rugae direction}

As shown in Tables 8 and 9, rugae direction was unchanged throughout the study $\left(\mathrm{T}_{1}, \mathrm{~T}_{2}\right.$, and $\left.\mathrm{T}_{3}\right)$ on both sides among males and females in Group 1 and 2 patients. Hence, $t$ and $P$ values cannot be computed.

\section{Effect of denture on rugae unification}

Rugae unification unchanged throughout the study $\left(\mathrm{T}_{1}\right.$, $\mathrm{T}_{2}$, and $\mathrm{T}_{3}$ ) on both sides among males and females in Group 1 and 2 patients. Hence, $t$ and $P$ values cannot be computed [Tables 10 and 11].

\section{Discussion}

Oral mucous membrane is not designed to provide foundation for a complete denture. Therefore, when under complete denture, it is called upon to function in a new environment. It is a common practice to select removable dentures for the prosthodontic rehabilitation of completely edentulous patients. However, the insertion 
Table 2. Effect of denture on Rugae number in Group 1 - Right and left side of palate

\begin{tabular}{|c|c|c|c|c|c|c|}
\hline \multirow[t]{2}{*}{ Types } & \multicolumn{4}{|c|}{ Mean \pm SD } & \multirow[t]{2}{*}{$t$} & \multirow[t]{2}{*}{$P$} \\
\hline & $\mathrm{T}_{0}$ & $\mathrm{~T}_{1}$ & $\mathrm{~T}_{2}$ & $\mathrm{~T}_{3}$ & & \\
\hline \multicolumn{7}{|l|}{ Right side } \\
\hline \multicolumn{7}{|l|}{ Primary } \\
\hline Male & $3.27 \pm 1.01$ & $3.27 \pm 1.01$ & $3.27 \pm 1.01$ & $3.27 \pm 1.01$ & - & - \\
\hline Female & $4.27 \pm 0.74$ & $4.27 \pm 0.74$ & $4.27 \pm 0.74$ & $4.27 \pm 0.74$ & - & - \\
\hline \multicolumn{7}{|c|}{ Secondary } \\
\hline Male & $0.47 \pm 0.57$ & $0.47 \pm 0.57$ & $0.47 \pm 0.57$ & $0.47 \pm 0.57$ & & - \\
\hline Female & $0.57 \pm 0.57$ & $0.57 \pm 0.57$ & $0.57 \pm 0.57$ & $0.57 \pm 0.57$ & - & - \\
\hline \multicolumn{7}{|c|}{ Fragmentary } \\
\hline Male & $0.17 \pm 0.38$ & $0.17 \pm 0.38$ & $0.17 \pm 0.38$ & $0.17 \pm 0.38$ & - & - \\
\hline Female & $0.27 \pm 0.45$ & $0.27 \pm 0.45$ & $0.27 \pm 0.45$ & $0.27 \pm 0.45$ & - & - \\
\hline \multicolumn{7}{|l|}{ Left side } \\
\hline \multicolumn{7}{|l|}{ Primary } \\
\hline Male & $3.60 \pm 0.81$ & $3.60 \pm 0.81$ & $3.60 \pm 0.81$ & $3.60 \pm 0.81$ & - & - \\
\hline Female & $4.57 \pm 0.50$ & $4.57 \pm 0.50$ & $4.57 \pm 0.50$ & $4.57 \pm 0.50$ & - & - \\
\hline \multicolumn{7}{|c|}{ Secondary } \\
\hline Male & $0.50 \pm 0.63$ & $0.50 \pm 0.63$ & $0.50 \pm 0.63$ & $0.50 \pm 0.63$ & - & - \\
\hline Female & $0.63 \pm 0.56$ & $0.63 \pm 0.56$ & $0.63 \pm 0.56$ & $0.63 \pm 0.56$ & - & - \\
\hline \multicolumn{7}{|c|}{ Fragmentary } \\
\hline Male & $0.20 \pm 0.41$ & $0.20 \pm 0.41$ & $0.20 \pm 0.41$ & $0.20 \pm 0.41$ & - & - \\
\hline Female & $0.33 \pm 0.48$ & $0.33 \pm 0.48$ & $0.33 \pm 0.48$ & $0.33 \pm 0.48$ & - & - \\
\hline
\end{tabular}

SD: Standard deviation

Table 3. Effect of denture on rugae number in Group 2 - Right and left side of palate

\begin{tabular}{|c|c|c|c|c|c|c|}
\hline \multirow[t]{2}{*}{ Types } & \multicolumn{4}{|c|}{ Mean \pm SD } & \multirow[t]{2}{*}{$t$} & \multirow[t]{2}{*}{$p$} \\
\hline & $\mathrm{T}_{0}$ & $\mathrm{~T}_{1}$ & $\mathrm{~T}_{2}$ & $\mathrm{~T}_{3}$ & & \\
\hline \multicolumn{7}{|l|}{ Right side } \\
\hline \multicolumn{7}{|l|}{ Primary } \\
\hline Male & $3.32 \pm 1.11$ & $3.32 \pm 1.11$ & $3.32 \pm 1.11$ & $3.32 \pm 1.11$ & - & - \\
\hline Female & $4.17 \pm 0.64$ & $4.17 \pm 0.64$ & $4.17 \pm 0.64$ & $4.17 \pm 0.64$ & - & - \\
\hline \multicolumn{7}{|c|}{ Secondary } \\
\hline Male & $0.49 \pm 0.51$ & $0.49 \pm 0.51$ & $0.49 \pm 0.51$ & $0.49 \pm 0.51$ & - & - \\
\hline Female & $0.54 \pm 0.59$ & $0.54 \pm 0.59$ & $0.54 \pm 0.59$ & $0.54 \pm 0.59$ & - & - \\
\hline \multicolumn{7}{|c|}{ Fragmentary } \\
\hline Male & $0.18 \pm 0.28$ & $0.18 \pm 0.28$ & $0.18 \pm 0.28$ & $0.18 \pm 0.28$ & - & - \\
\hline Female & $0.29 \pm 0.35$ & $0.29 \pm 0.35$ & $0.29 \pm 0.35$ & $0.29 \pm 0.35$ & - & - \\
\hline \multicolumn{7}{|l|}{ Left side } \\
\hline \multicolumn{7}{|l|}{ Primary } \\
\hline Male & $3.65 \pm 0.87$ & $3.65 \pm 0.87$ & $3.65 \pm 0.87$ & $3.65 \pm 0.87$ & - & - \\
\hline Female & $4.37 \pm 0.60$ & $4.37 \pm 0.60$ & $4.37 \pm 0.60$ & $4.37 \pm 0.60$ & - & - \\
\hline Secondar & & & & & & \\
\hline
\end{tabular}




\begin{tabular}{|c|c|c|c|c|c|c|}
\hline Male & $0.60 \pm 0.83$ & $0.60 \pm 0.83$ & $0.60 \pm 0.83$ & $0.60 \pm 0.83$ & - & - \\
\hline Female & $0.73 \pm 0.56$ & $0.73 \pm 0.56$ & $0.73 \pm 0.56$ & $0.73 \pm 0.56$ & - & - \\
\hline \multicolumn{7}{|c|}{ Fragmentary } \\
\hline Male & $0.30 \pm 0.51$ & $0.30 \pm 0.51$ & $0.30 \pm 0.51$ & $0.30 \pm 0.51$ & - & - \\
\hline Female & $0.43 \pm 0.58$ & $0.43 \pm 0.58$ & $0.43 \pm 0.58$ & $0.43 \pm 0.58$ & - & - \\
\hline
\end{tabular}

SD: Standard deviation

Table 4. Effect of denture on rugae length in Group 1- Right and left side of palate

\begin{tabular}{|c|c|c|c|c|c|c|}
\hline \multirow[t]{2}{*}{ Types } & \multicolumn{4}{|c|}{ Mean \pm SD } & \multirow[t]{2}{*}{$t$} & \multirow[t]{2}{*}{$P$} \\
\hline & $\mathrm{T}_{0}$ & $T_{1}$ & $\mathrm{~T}_{2}$ & $\mathrm{~T}_{3}$ & & \\
\hline \multicolumn{7}{|l|}{ Right side } \\
\hline \multicolumn{7}{|l|}{ Primary } \\
\hline Male & $11.72 \pm 2.65$ & $11.71 \pm 2.65$ & $11.69 \pm 2.67$ & $11.58 \pm 2.68$ & 27.21 & $<0.001$ \\
\hline Female & 12.122 .78 & $12.12 \pm 2.78$ & $12.10 \pm 2.79$ & $12.02 \pm 2.68$ & 13.19 & $<0.001$ \\
\hline \multicolumn{7}{|c|}{ Secondary } \\
\hline Male & $04.13 \pm 0.54$ & $04.13 \pm 0.54$ & $04.12 \pm 0.54$ & $04.11 \pm 0.55$ & 1.87 & 0.080 \\
\hline Female & 04.652 .70 & $04.65 \pm 2.70$ & $04.63 \pm 2.71$ & $04.63 \pm 2.71$ & 1.80 & 0.073 \\
\hline \multicolumn{7}{|c|}{ Fragmentary } \\
\hline Male & $02.43 \pm 0.31$ & $02.42 \pm 0.31$ & $02.42 \pm 0.31$ & $02.41 \pm 0.32$ & 0.14 & 0.89 \\
\hline Female & $02.46 \pm 0.32$ & $02.46 \pm 0.32$ & $02.45 \pm 0.32$ & $02.44 \pm 0.33$ & 0.18 & 0.63 \\
\hline \multicolumn{7}{|l|}{ Left side } \\
\hline \multicolumn{7}{|l|}{ Primary } \\
\hline Male & $11.65 \pm 2.70$ & $11.64 \pm 2.70$ & $11.62 \pm 2.71$ & $11.51 \pm 2.77$ & 35.07 & $<0.001$ \\
\hline Female & $12.17 \pm 2.70$ & $12.17 \pm 2.70$ & $12.14 \pm 2.72$ & $12.03 \pm 2.75$ & 24.70 & $<0.001$ \\
\hline \multicolumn{7}{|c|}{ Secondary } \\
\hline Male & $04.13 \pm 0.54$ & $04.13 \pm 0.54$ & $04.12 \pm 0.54$ & $04.10 \pm 0.55$ & 1.72 & 0.087 \\
\hline Female & $04.68 \pm 0.51$ & $04.68 \pm 0.51$ & $04.67 \pm 0.52$ & $04.65 \pm 0.53$ & 1.87 & 0.080 \\
\hline \multicolumn{7}{|c|}{ Fragmentary } \\
\hline Male & $02.45 \pm 0.30$ & $02.45 \pm 0.30$ & $02.45 \pm 0.30$ & $02.44 \pm 0.30$ & 0.15 & 0.87 \\
\hline Female & $02.47 \pm 0.31$ & $02.47 \pm 0.31$ & $02.47 \pm 0.31$ & $02.46 \pm 0.30$ & 0.19 & 0.61 \\
\hline
\end{tabular}

SD: Standard deviation

Table 5. Effect of denture on rugae length in Group -2 - Right and left side of palate

\begin{tabular}{lcccc}
\hline Types & \multicolumn{4}{c}{ Mean \pm SD } \\
\cline { 2 - 5 } & $\mathrm{T}_{0}$ & $\mathrm{~T}_{1}$ & $\mathrm{~T}_{2}$ & $\mathrm{~T}_{3}$ \\
\hline $\begin{array}{c}\text { Right side } \\
\text { Primary } \\
\text { Male }\end{array}$ & & & & \\
$\quad$ Female & $11.56 \pm 2.55$ & $11.56 \pm 2.55$ & $11.56 \pm 2.55$ & $11.56 \pm 2.55$ \\
Secondary & $12.72 \pm 2.98$ & $12.72 \pm 2.98$ & $12.72 \pm 2.98$ & $12.72 \pm 2.98$ \\
$\quad$ Male & & & & \\
$\quad$ Female & $05.13 \pm 0.44$ & $05.13 \pm 0.44$ & $05.13 \pm 0.44$ & $05.13 \pm 0.44$ \\
Fragmentary & $03.65 \pm 2.80$ & $03.65 \pm 2.80$ & $03.65 \pm 2.80$ & $03.65 \pm 2.80$ \\
$\quad$ Male & & & & \\
$\quad$ Female & $02.33 \pm 0.27$ & $02.33 \pm 0.27$ & $02.33 \pm 0.27$ & $02.33 \pm 0.27$ \\
Left side & $02.86 \pm 0.48$ & $02.86 \pm 0.48$ & $02.86 \pm 0.48$ & $02.86 \pm 0.48$ \\
Primary & & & & \\
$\quad$ Male & & & & \\
& $12.65 \pm 1.70$ & $12.65 \pm 1.70$ & $12.65 \pm 1.70$ & $12.65 \pm 1.70$
\end{tabular}




\begin{tabular}{lllllll} 
Female & $13.17 \pm 2.10$ & $13.17 \pm 2.10$ & $13.17 \pm 2.10$ & $13.17 \pm 2.10$ & - & - \\
Secondary & & & & & & - \\
Male & $03.23 \pm 0.44$ & $03.23 \pm 0.44$ & $03.23 \pm 0.44$ & $03.23 \pm 0.44$ & - & - \\
Female & $03.68 \pm 0.61$ & $03.68 \pm 0.61$ & $03.68 \pm 0.61$ & $03.68 \pm 0.61$ & - & - \\
Fragmentary & & & & & & - \\
Male & $02.25 \pm 0.10$ & $02.25 \pm 0.10$ & $02.25 \pm 0.10$ & $02.25 \pm 0.10$ & - & - \\
Female & $02.37 \pm 0.21$ & $02.37 \pm 0.21$ & $02.37 \pm 0.21$ & $02.37 \pm 0.21$ & - & - \\
\hline
\end{tabular}

SD: Standard deviation

Table 6. Effect of denture on rugae shape in Group 1 - Right and left side of the palate

\begin{tabular}{|c|c|c|c|c|c|c|}
\hline \multirow[t]{2}{*}{ Shape } & \multicolumn{4}{|c|}{ Mean \pm SD } & \multirow[t]{2}{*}{$t$} & \multirow[t]{2}{*}{$P$} \\
\hline & $\mathrm{T}_{0}$ & $\mathrm{~T}_{1}$ & $\mathrm{~T}_{2}$ & $\mathrm{~T}_{3}$ & & \\
\hline \multicolumn{7}{|l|}{ Right side } \\
\hline \multicolumn{7}{|l|}{ Curved } \\
\hline Male & $0.97 \pm 0.85$ & $0.97 \pm 0.85$ & $0.97 \pm 0.85$ & $1.07 \pm 0.91$ & 1.79 & 0.08 \\
\hline Female & $1.27 \pm 0.74$ & $1.27 \pm 0.74$ & $1.27 \pm 0.74$ & $1.33 \pm 0.84$ & 1.43 & 0.16 \\
\hline \multicolumn{7}{|l|}{ Wavy } \\
\hline Male & $1.73 \pm 0.98$ & $1.73 \pm 0.98$ & $1.73 \pm 0.98$ & $1.63 \pm 1.00$ & 1.79 & 0.08 \\
\hline Female & $2.20 \pm 0.71$ & $2.20 \pm 0.71$ & $2.20 \pm 0.71$ & $2.13 \pm 0.73$ & 1.43 & 0.16 \\
\hline \multicolumn{7}{|l|}{ Straight } \\
\hline Male & $0.47 \pm 0.63$ & $0.47 \pm 0.63$ & $0.47 \pm 0.63$ & $0.47 \pm 0.63$ & - & - \\
\hline Female & $0.67 \pm 0.71$ & $0.67 \pm 0.71$ & $0.67 \pm 0.71$ & $0.67 \pm 0.71$ & - & - \\
\hline \multicolumn{7}{|l|}{ Circular } \\
\hline Male & $0.10 \pm 0.31$ & $0.10 \pm 0.31$ & $0.10 \pm 0.31$ & $0.10 \pm 0.31$ & - & - \\
\hline Female & $0.13 \pm 0.35$ & $0.13 \pm 0.35$ & $0.13 \pm 0.35$ & $0.13 \pm 0.35$ & - & - \\
\hline \multicolumn{7}{|l|}{ Left side } \\
\hline \multicolumn{7}{|l|}{ Curved } \\
\hline Male & $1.07 \pm 0.69$ & $1.07 \pm 0.69$ & $1.07 \pm 0.69$ & $1.13 \pm 0.78$ & 1.43 & 0.16 \\
\hline Female & $1.33 \pm 0.66$ & $1.33 \pm 0.66$ & $1.33 \pm 0.66$ & $1.43 \pm 0.73$ & 1.79 & 0.08 \\
\hline \multicolumn{7}{|l|}{ Wavy } \\
\hline Male & $1.83 \pm 0.87$ & $1.83 \pm 0.87$ & $1.83 \pm 0.87$ & $1.77 \pm 0.97$ & 1.44 & 0.16 \\
\hline Female & $2.30 \pm 0.65$ & $2.30 \pm 0.65$ & $2.30 \pm 0.65$ & $2.20 \pm 0.76$ & 1.43 & 0.16 \\
\hline \multicolumn{7}{|l|}{ Straight } \\
\hline Male & $0.57 \pm 0.68$ & $0.57 \pm 0.68$ & $0.57 \pm 0.68$ & $0.57 \pm 0.68$ & - & - \\
\hline Female & $0.73 \pm 0.78$ & $0.73 \pm 0.78$ & $0.73 \pm 0.78$ & $0.73 \pm 0.78$ & - & - \\
\hline \multicolumn{7}{|l|}{ Circular } \\
\hline Male & $0.07 \pm 0.25$ & $0.07 \pm 0.25$ & $0.07 \pm 0.25$ & $0.07 \pm 0.25$ & - & - \\
\hline Female & $0.23 \pm 0.43$ & $0.23 \pm 0.43$ & $0.23 \pm 0.43$ & $0.23 \pm 0.43$ & - & - \\
\hline
\end{tabular}

SD: Standard deviation

of such a denture base sometimes gives formation of depression on the mucous membrane. Many studies have explored the histologic effects on underlying soft tissues, demonstrating deformed epithelial ridges of the mucosa, degeneration of epithelial cells, changes in fibers of the connective tissues, alveolar bone resorption, and effects on the neurosensory system.

Palatoscopy or palatal rugoscopy is the name given to the study of palatal rugae to establish individual identity. ${ }^{13}$
Palatal rugae are highly individualistic and consistent in shape throughout life. The orientation and forms of palatal rugae are governed by the core fibers running anterioposteriorly in concentric circles below each rugae. Fibroblasts and collagen fibers then accumulate in the connective tissue beneath the thickened epithelium and assume distinct orientation. The core within the palatal rugae of humans contains elements that are believed to contribute to the maintenance of its shape. The main 
Table 7. Effect of denture on rugae shape in Group 2 - Right and left side of the palate

\begin{tabular}{|c|c|c|c|c|c|c|}
\hline \multirow[t]{2}{*}{ Shape } & \multicolumn{4}{|c|}{ Mean \pm SD } & \multirow[t]{2}{*}{$t$} & \multirow[t]{2}{*}{$P$} \\
\hline & $\mathrm{T}_{0}$ & $\mathrm{~T}_{1}$ & $\mathrm{~T}_{2}$ & $\mathrm{~T}_{3}$ & & \\
\hline \multicolumn{7}{|l|}{ Right side } \\
\hline \multicolumn{7}{|l|}{ Curved } \\
\hline Male & $0.87 \pm 0.65$ & $0.87 \pm 0.65$ & $0.87 \pm 0.65$ & $0.87 \pm 0.65$ & - & - \\
\hline Female & $1.17 \pm 0.64$ & $1.17 \pm 0.64$ & $1.17 \pm 0.64$ & $1.17 \pm 0.64$ & - & - \\
\hline \multicolumn{7}{|l|}{ Wavy } \\
\hline Male & $1.93 \pm 0.78$ & $1.93 \pm 0.78$ & $1.93 \pm 0.78$ & $1.93 \pm 0.78$ & - & - \\
\hline Female & $2.10 \pm 0.81$ & $2.10 \pm 0.81$ & $2.10 \pm 0.81$ & $2.10 \pm 0.81$ & - & - \\
\hline \multicolumn{7}{|l|}{ Straight } \\
\hline Male & $0.37 \pm 0.43$ & $0.37 \pm 0.43$ & $0.37 \pm 0.43$ & $0.37 \pm 0.43$ & - & - \\
\hline Female & $0.57 \pm 0.61$ & $0.57 \pm 0.61$ & $0.57 \pm 0.61$ & $0.57 \pm 0.61$ & - & - \\
\hline \multicolumn{7}{|l|}{ Circular } \\
\hline Male & $0.12 \pm 0.11$ & $0.12 \pm 0.11$ & $0.12 \pm 0.11$ & $0.12 \pm 0.11$ & - & - \\
\hline Female & $0.15 \pm 0.24$ & $0.15 \pm 0.24$ & $0.15 \pm 0.24$ & $0.15 \pm 0.24$ & - & - \\
\hline \multicolumn{7}{|l|}{ Left side } \\
\hline \multicolumn{7}{|l|}{ Curved } \\
\hline Male & $1.17 \pm 0.49$ & $1.17 \pm 0.49$ & $1.17 \pm 0.49$ & $1.17 \pm 0.49$ & - & - \\
\hline Female & $1.39 \pm 0.56$ & $1.39 \pm 0.56$ & $1.39 \pm 0.56$ & $1.39 \pm 0.56$ & - & - \\
\hline \multicolumn{7}{|l|}{ Wavy } \\
\hline Male & $1.93 \pm 0.77$ & $1.93 \pm 0.77$ & $1.93 \pm 0.77$ & $1.93 \pm 0.77$ & - & - \\
\hline Female & $2.40 \pm 0.65$ & $2.40 \pm 0.65$ & $2.40 \pm 0.65$ & $2.40 \pm 0.65$ & - & - \\
\hline \multicolumn{7}{|l|}{ Straight } \\
\hline Male & $0.47 \pm 0.58$ & $0.47 \pm 0.58$ & $0.47 \pm 0.58$ & $0.47 \pm 0.58$ & - & - \\
\hline Female & $0.63 \pm 0.88$ & $0.63 \pm 0.88$ & $0.63 \pm 0.88$ & $0.63 \pm 0.88$ & - & - \\
\hline \multicolumn{7}{|l|}{ Circular } \\
\hline Male & $0.17 \pm 0.15$ & $0.17 \pm 0.15$ & $0.17 \pm 0.15$ & $0.17 \pm 0.15$ & - & - \\
\hline Female & $0.25 \pm 0.13$ & $0.25 \pm 0.13$ & $0.25 \pm 0.13$ & $0.25 \pm 0.13$ & - & - \\
\hline
\end{tabular}

SD: Standard deviation

Table 8. Effect of denture on Rugae direction in Group 1 - Right and left side of the palate

\begin{tabular}{|c|c|c|c|c|c|c|}
\hline \multirow[t]{2}{*}{ Direction } & \multicolumn{4}{|c|}{ Mean \pm SD } & \multirow[t]{2}{*}{$t$} & \multirow[t]{2}{*}{$P$} \\
\hline & $\mathrm{T}_{0}$ & $\mathrm{~T}_{1}$ & $\mathrm{~T}_{2}$ & $\mathrm{~T}_{3}$ & & \\
\hline \multicolumn{7}{|l|}{ Right side } \\
\hline \multicolumn{7}{|l|}{ Forwardly } \\
\hline Male & $1.20 \pm 0.41$ & $1.20 \pm 0.41$ & $1.20 \pm 0.41$ & $1.20 \pm 0.41$ & - & - \\
\hline Female & $1.93 \pm 0.94$ & $1.93 \pm 0.94$ & $1.93 \pm 0.94$ & $1.93 \pm 0.94$ & - & - \\
\hline \multicolumn{7}{|l|}{ Backwardly } \\
\hline Male & $0.87 \pm 0.73$ & $0.87 \pm 0.73$ & $0.87 \pm 0.73$ & $0.87 \pm 0.73$ & - & - \\
\hline Female & $1.10 \pm 0.99$ & $1.10 \pm 0.99$ & $1.10 \pm 0.99$ & $1.10 \pm 0.99$ & - & - \\
\hline Perpendicular & 11 & & & & & \\
\hline Male & $0.20 \pm 0.41$ & $20 \pm 0.41$ & $20 \pm 0.41$ & $20 \pm 0.41$ & - & - \\
\hline Female & $0.33 \pm 0.56$ & $0.33 \pm 0.56$ & $0.33 \pm 0.56$ & $0.33 \pm 0.56$ & - & - \\
\hline \multicolumn{7}{|l|}{ Left side } \\
\hline \multicolumn{7}{|l|}{ Forwardly } \\
\hline Male & $1.40 \pm 0.97$ & $1.40 \pm 0.97$ & $1.40 \pm 0.97$ & $1.40 \pm 0.97$ & - & - \\
\hline Female & $2.30 \pm 1.12$ & $2.30 \pm 1.12$ & $2.30 \pm 1.12$ & $2.30 \pm 1.12$ & - & - \\
\hline
\end{tabular}




\begin{tabular}{|c|c|c|c|c|c|c|}
\hline \multicolumn{7}{|c|}{ Backwardly } \\
\hline Male & $0.87 \pm 1.04$ & $0.87 \pm 1.04$ & $0.87 \pm 1.04$ & $0.87 \pm 1.04$ & - & - \\
\hline Female & $1.27 \pm 1.14$ & $1.27 \pm 1.14$ & $1.27 \pm 1.14$ & $1.27 \pm 1.14$ & - & - \\
\hline \multicolumn{7}{|c|}{ Perpendicular } \\
\hline Male & $0.27 \pm 0.45$ & $0.27 \pm 0.45$ & $0.27 \pm 0.45$ & $0.27 \pm 0.45$ & - & - \\
\hline Female & $0.37 \pm 0.55$ & $0.37 \pm 0.55$ & $0.37 \pm 0.55$ & $0.37 \pm 0.55$ & - & - \\
\hline
\end{tabular}

SD: Standard deviation

Table 9. Effect of denture on rugae direction in Group 2 - Right and left side of the palate

\begin{tabular}{|c|c|c|c|c|c|c|}
\hline \multirow[t]{2}{*}{ Direction } & \multicolumn{4}{|c|}{ Mean \pm SD } & \multirow[t]{2}{*}{$t$} & \multirow[t]{2}{*}{$p$} \\
\hline & $\mathrm{T}_{0}$ & $\mathrm{~T}_{1}$ & $\mathrm{~T}_{2}$ & $\mathrm{~T}_{3}$ & & \\
\hline \multicolumn{7}{|l|}{ Right side } \\
\hline \multicolumn{7}{|l|}{ Forwardly } \\
\hline Male & $1.10 \pm 0.31$ & $1.10 \pm 0.31$ & $1.10 \pm 0.31$ & $1.10 \pm 0.31$ & - & - \\
\hline Female & $1.95 \pm 0.97$ & $1.95 \pm 0.97$ & $1.95 \pm 0.97$ & $1.95 \pm 0.97$ & - & - \\
\hline \multicolumn{7}{|c|}{ Backwardly } \\
\hline Male & $0.89 \pm 0.63$ & $0.89 \pm 0.63$ & $0.89 \pm 0.63$ & $0.89 \pm 0.63$ & - & - \\
\hline Female & $1.15 \pm 0.50$ & $1.15 \pm 0.50$ & $1.15 \pm 0.50$ & $1.15 \pm 0.50$ & - & - \\
\hline \multicolumn{7}{|c|}{ Perpendicular } \\
\hline Male & $0.23 \pm 0.31$ & $0.23 \pm 0.31$ & $0.23 \pm 0.31$ & $0.23 \pm 0.31$ & - & - \\
\hline Female & $0.31 \pm 0.46$ & $0.31 \pm 0.46$ & $0.31 \pm 0.46$ & $0.31 \pm 0.46$ & - & - \\
\hline \multicolumn{7}{|l|}{ Left side } \\
\hline \multicolumn{7}{|c|}{ Forwardly } \\
\hline Male & $1.30 \pm 0.87$ & $1.30 \pm 0.87$ & $1.30 \pm 0.87$ & $1.30 \pm 0.87$ & - & - \\
\hline Female & $2.10 \pm 1.12$ & $2.10 \pm 1.12$ & $2.10 \pm 1.12$ & $2.10 \pm 1.12$ & - & - \\
\hline \multicolumn{7}{|c|}{ Backwardly } \\
\hline Male & $0.87 \pm 1.01$ & $0.87 \pm 1.01$ & $0.87 \pm 1.01$ & $0.87 \pm 1.01$ & - & - \\
\hline Female & $1.18 \pm 1.04$ & $1.18 \pm 1.04$ & $1.18 \pm 1.04$ & $1.18 \pm 1.04$ & - & - \\
\hline \multicolumn{7}{|c|}{ Perpendicular } \\
\hline Male & $0.17 \pm 0.25$ & $0.17 \pm 0.25$ & $0.17 \pm 0.25$ & $0.17 \pm 0.25$ & - & - \\
\hline Female & $0.29 \pm 0.35$ & $0.29 \pm 0.35$ & $0.29 \pm 0.35$ & $0.29 \pm 0.35$ & - & - \\
\hline
\end{tabular}

SD: Standard deviation

structural element of rugae contains glycosaminoglycans which by its hydrophilic nature causes the tissue to swell and contributes to the maintenance of the shape of rugae throughout life. ${ }^{14}$

Leonstinis ascertained that characteristic pattern of the palatal rugae did not change as a result of growth, and remain stable from the time of development until the oral mucosa degenerated at death. ${ }^{15,16}$ Controversy still exists about the stability of quantitative and qualitative characteristics of rugae during growth, and the extent of differences between ethnic groups and sexes. The mean rugae count changes moderately in adolescence, then increases, markedly from the age of 35-40 years. ${ }^{17}$ In contrast according to Lysell, the number of rugae decreased from 23 years of age onwards. ${ }^{14}$ The changes in the length of rugae with age result from underlying palatal growth. According to Vander Linden, the anterior rugae does not increase in length after 10 years of age, whereas other qualitative characteristics such as shape, direction, and unification remain stable throughout life. ${ }^{14}$ 
Table 10. Effect of denture on Rugae unification in Group 1 - Right and left side of the palate

\begin{tabular}{|c|c|c|c|c|c|c|}
\hline \multirow[t]{2}{*}{ Unification } & \multicolumn{4}{|c|}{ Mean \pm SD } & \multirow[t]{2}{*}{$t$} & \multirow[t]{2}{*}{$P$} \\
\hline & $\mathrm{T}_{0}$ & $\mathrm{~T}_{1}$ & $\mathrm{~T}_{2}$ & $\mathrm{~T}_{3}$ & & \\
\hline \multicolumn{7}{|l|}{ Right side } \\
\hline \multicolumn{7}{|l|}{ Converging } \\
\hline Male & $1.04 \pm 0.73$ & $1.04 \pm 0.73$ & $1.04 \pm 0.73$ & $1.04 \pm 0.73$ & - & - \\
\hline Female & $0.48 \pm 0.51$ & $0.48 \pm 0.51$ & $0.48 \pm 0.51$ & $0.48 \pm 0.51$ & - & - \\
\hline \multicolumn{7}{|l|}{ Diverging } \\
\hline Male & $0.52 \pm 0.51$ & $0.52 \pm 0.51$ & $0.52 \pm 0.51$ & $0.52 \pm 0.51$ & - & - \\
\hline Female & $0.81 \pm 0.65$ & $0.81 \pm 0.65$ & $0.81 \pm 0.65$ & $0.81 \pm 0.65$ & - & - \\
\hline \multicolumn{7}{|l|}{ Left side } \\
\hline Converging & $0.88 \pm 0.73$ & $0.88 \pm 0.73$ & $0.88 \pm 0.73$ & $0.88 \pm 0.73$ & - & - \\
\hline Male & $0.48 \pm 0.51$ & $0.48 \pm 0.51$ & $0.48 \pm 0.51$ & $0.48 \pm 0.51$ & - & - \\
\hline \multirow{2}{*}{\multicolumn{7}{|c|}{$\begin{array}{l}\text { Female } \\
\text { Diverging }\end{array}$}} \\
\hline & & & & & & \\
\hline Male & $0.51 \pm 0.57$ & $0.51 \pm 0.57$ & $0.51 \pm 0.57$ & $0.51 \pm 0.57$ & - & - \\
\hline Female & $0.80 \pm 0.82$ & $0.80 \pm 0.82$ & $0.80 \pm 0.82$ & $0.80 \pm 0.82$ & - & - \\
\hline
\end{tabular}

SD: Standard deviation

Table 11. Effect of denture on Rugae unification in Group 2 - Right and left side of palate

\begin{tabular}{|c|c|c|c|c|c|c|}
\hline \multirow[t]{2}{*}{ Unification } & \multicolumn{4}{|c|}{ Mean \pm SD } & \multirow[t]{2}{*}{$t$} & \multirow[t]{2}{*}{$P$} \\
\hline & $\mathrm{T}_{0}$ & $\mathrm{~T}_{1}$ & $\mathrm{~T}_{2}$ & $\mathrm{~T}_{3}$ & & \\
\hline \multicolumn{7}{|l|}{ Right side } \\
\hline \multicolumn{7}{|l|}{ Converging } \\
\hline Male & $1.40 \pm 0.62$ & $1.40 \pm 0.62$ & $1.40 \pm 0.62$ & $1.40 \pm 0.62$ & - & - \\
\hline Female & $0.58 \pm 0.61$ & $0.58 \pm 0.61$ & $0.58 \pm 0.61$ & $0.58 \pm 0.61$ & - & - \\
\hline \multicolumn{7}{|l|}{ Diverging } \\
\hline Male & $0.55 \pm 0.40$ & $0.55 \pm 0.40$ & $0.55 \pm 0.40$ & $0.55 \pm 0.40$ & - & - \\
\hline Female & $0.91 \pm 0.55$ & $0.91 \pm 0.55$ & $0.91 \pm 0.55$ & $0.91 \pm 0.55$ & - & - \\
\hline \multicolumn{7}{|l|}{ Left side } \\
\hline Converging & $0.91 \pm 0.63$ & $0.91 \pm 0.63$ & $0.91 \pm 0.63$ & $0.91 \pm 0.63$ & - & - \\
\hline Male & $0.58 \pm 0.41$ & $0.58 \pm 0.41$ & $0.58 \pm 0.41$ & $0.58 \pm 0.41$ & - & - \\
\hline \multicolumn{7}{|l|}{$\begin{array}{l}\text { Female } \\
\text { Diverging }\end{array}$} \\
\hline Diverging & & & & & & \\
\hline Male & $0.53 \pm 0.47$ & $0.53 \pm 0.47$ & $0.53 \pm 0.47$ & $0.53 \pm 0.47$ & - & - \\
\hline Female & $0.81 \pm 0.62$ & $0.81 \pm 0.62$ & $0.81 \pm 0.62$ & $0.81 \pm 0.62$ & - & - \\
\hline
\end{tabular}

SD: Standard deviation

Events such as trauma, extreme finger sucking in infancy, and persistent pressure with orthodontic treatment and dentures contribute to the change in rugae patterns.

Brinch was the first to study the tissue changes under dentures by histological method. ${ }^{18}$ Mentz found that the changes of the mucous membrane were concentrated in the epithelium which increase in volume and become hyperkeratotic. ${ }^{18}$ Pendeton found parakeratosis in some and keratinization and nonkeratinization in others. ${ }^{19}$ Kapur and Gerland revealed that denture stimulates keratinization. ${ }^{20}$ Truck observed an increase in the thickness of the stratum corneum in removable partial denture users. ${ }^{21}$ Ostlund reported a decrease in thickness of the stratum corneum under complete dentures and 
disappearance of the horny layer from epithelium, resulting in parakeratosis. Nedelman and associates, in a histochemical study, observed thickening of keratinized layer in nondenture wearers and thinning of this layer in denture wearers. ${ }^{22} \mathrm{~A}$ report of Choudhury and Boucher shows that dentures do affect the thickness of stratum corneum. ${ }^{18}$

The present study was an attempt to evaluate the effect of denture on palatal rugae pattern. Hence, in our study, subjects in the sample were above the 45 years of age with equal gender distribution and all are from the coastal areas of Andhra Pradesh. Various methods of palatal rugae analysis are available currently. In this study, dental casts were used for rugae analysis because they simplify analysis, reduce cost, and can be easily done in any laboratory. For a more accurate result, the use of cast made from jaws rather than the dentures were suggested. ${ }^{14}$ Several studies have shown the use of photographs taken by digital camera, their transfer to hard disk of computer followed by analysis using a software program. This process can conserve the physical space consumed for storing cast and this process is complex. In this study, to avoid the errors, alignate impression material which is mucostatic to obtain pressure-less impression and type III dental stone is used due to low setting expansion. ${ }^{10}$ Eye strain was a problem and rest intervals were required to minimize the errors that could occur if the quantitative scale was retained. For measuring the length, a brass wire is used which is stable, moldable and digital Vernier caliper is used instead of manual scale for accurate measurement. Several classifications have been devised by various authors to record the palatal rugae patterns; among them, the Thomas and Kotze, Kapali, Trobo classifications are often used in recording the patterns. After a thorough review of all classifications in literature, Thomas and Kotze classification was used in the present study which is most practical and easy to apply compared with other methods. To eliminate interobserver error, a single operator alone was suggested.

In the present study, gradual decrease in the primary rugae length was observed in experimental population after wearing denture (group I) which is statistically significant for both genders $(P<0.001)$. In secondary and fragmentary rugae also, decrease in the rugae length was observed, but it is not significant $(P>0.05)$ for both genders. This may be due to entire masticatory load distribution over the palatal mucosa and residual ridges after wearing dentures, ${ }^{18}$ whereas in control group, no change in the rugae length was observed. In dentulous people, the masticatory stresses are borne by teeth and supporting tissues. ${ }^{18}$ The change in primary rugae length was more in males $(t=27.21)$ than females $(t=$ 13.19). This may be due to gender related differences in masticatory performance, i.e., maximum occlusal forces were larger in males compared to females. ${ }^{23}$

Kydd and Austin reported that sustained mechanical stress posed by dentures on the palatal mucosa leads to the contraction of epithelial ridges subjacent to the pressure-loaded region. ${ }^{24,25}$ Kanabayashi reported that cells of the prickle cell layer and upper layers of the epithelium remained unchanged, while cells of the basal layer were prone to atrophy in the pressure loaded region of the epithelium of the palatal mucosa under an inserted experimental palate. ${ }^{24}$ Ichihara also suggested that cells of the epithelial basal layer are more vulnerable to mechanical stress than are those of the overlying layers. ${ }^{24}$ Sharma et al. reported the changes in fiber content of connective tissues in palatal mucosa under denture. ${ }^{26}$ Ishizaki et al. proved that there is decrease in the number of Merkel cells in palatal rugae due to continuous mechanical stimulation by the palatal plate. ${ }^{24}$ In consideration with the abovementioned studies, changes in the rugae length may be due to histological changes.

There is slight change in the shape of rugae, especially wavy and curved rugae at $\mathrm{T}_{3}$ session when compared to previous sessions such as $\mathrm{T}_{0}, \mathrm{~T}_{1}$, and $\mathrm{T}_{2}$ in denture wearers, but statistically insignificant $(P>0.05)$. There is no change in the number, direction, and unification of rugae in both experimental (group 1) and control (group 2) population throughout the study in both genders.

\section{Conclusions}

Although researches have confirmed the potential value of rugae in personal identification, it has more of comparative value and needs stored data in the form of casts or photographs to compare with the suspects when the need arises. Rugae pattern are complex and open to individual interpretation. It is envisaged that a single operator alone should use the given classification successfully and apply it in a comparative project. Although some changes do occur in few parameters of rugae after denture wearing the other parameters remain stable throughout life and may be important for identification when there is antimortem 
information available for comparison. However, further research is necessary with large sample size and time period to substantiate the findings of present studies.

Nevertheless, palatal rugae may serve as an adjuvant to other techniques such as DNA analysis and finger prints in forensic investigations.

\section{Financial Support and Sponsorship}

Nil.

\section{Conflicts of Interest}

There are no conflicts of interest.

\section{Acknownlegement}

We would like to thank for Bishop Jaya Rao Polimera, Chairman of St. Joseph Dental College, Eluru for giving support and Dr. Ashith B. Acharya, Professor and Head of Department, Forensic Odontology, SDM Dental college, Dharwad for giving latest information on this study.

\section{References}

1. Bhullar A, Kaur RP, Kamat MS. Palatal rugea - An aid in clinical dentistry. J Forensic Res 2011;2:1-4.

2. Heartwell CM, Rahn AO. Syllabus of Complete Dentures. 3rd ed. Philadelphia: Lea \& Febriger; 1980.

3. Zarb GA, Bolender CL, Carlsson GE. Boucher's Prosthodontic Treatment for Edentulous Patients. 13th ed. Missouri: Mosby Inc., St. Louis; 2012.

4. Avant WE. Indirect retention in partial denture design. J Prosth Dent 2003;90:1-5.

5. Shailaja AM, Romana IRU, Narayanappa G, Smitha T, Gowda NC, Vedavathi HK. Assessment of palatal rugae pattern and its significance in orthodontics and forensic odontology. J Oral Maxillofac Pathol 2018;22:430-5.

6. Li B, Tae-Geon K, Wu X, Hee-Moon K, Ke-Ming Y, Xiu-Ping W. Model analysis of anatomical morphology changes of palatal rugae before and after orthodontic treatment. Int J Morphol 2017;35:1224-9.

7. Pappu BT, Gopinathan TA, Naduvakattu B. Assessment of different palatal rugae patterns in gender identification. Int J Oral Care Res 2018;6:17-20.
8. Mustafa AG, Allouh MZ, Alshehab RM. Morphological changes in palatal rugae patterns following orthodontic treatment. J Forensic Leg Med 2015;31:19-22.

9. Kerr DA, Ash MM, Millard HD. Oral Diagnosis. 6th ed. USA: C. V. Mosby Company; 1983. p. 82-150.

10. Anusavice KJ. Gypsum products. In: Anusavice KJ, editor. Phillips Science of Dental Materials. 12th ed. Saunders: St Louis; 2013.

11. Tueller VM. Impression material and technique. In: Rhoades JE, Rudd KD, Morrow RM, editors. Dental Laboratory Procedures: Fixed Partial Dentures. 2nd ed. St Louis: Mosby, St Louis; 1983. p. 112.

12. Lefler BB, Reddy TG. Working casts and dies. In: Rhoades JE, Rudd KD, Morrow RM, editors. Dental Laboratory Procedures: Fixed Partial Dentures. 2nd ed. St Louis: Mosby, St Louis; 1983. p. 334.

13. Indira A, Gupta M, David MP. Usefulness of palatal rugae patterns in establishing identity: Preliminary results from Bengaluru city, India. J Forensic Dent Sci 2012;4:2-5.

14. Rajan VP, John JB, Stalin A, Priya G, Abuthagir AK. Morphology of palatal rugae patterns among 5-15 years old children. J Pharm Bioallied Sci 2013;5:S43-7.

15. Peavy DC Jr., Kendrick GS. The effects of tooth movement on the palatine rugae. J Prosthet Dent 1967;18:536-42.

16. English WR, Robinson SF, Summitt JB, Osterle LJ, Brannon $\mathrm{RB}$, Morlang WM. Individuality of human palate rugae. J Forensic Sci 1988;33:718-26.

17. Hauser G, Daponte A, Roberts MJ. Palatal rugae. J Anat 1989;165:237-49.

18. Jani RM, Bhargava K. A histologic comparison of palatal mucosa before and after wearing complete dentures. J Prosthet Dent 1976;36:254-60.

19. Pendleton EC. Changes in the denture supporting tissues. J Am Dent Assoc 1951;42:1-15.

20. Kapur S, Gerald S. The effect of denture on alveolar mucosa. J Prosthet Dent 1963;13:1030-7.

21. Turck D. A histologic comparison of the edentulous denture and non-denture bearing tissues. J Prosthet Dent 1965;15:419-34.

22. Ostlund SG. Effect of complete dentures on the gum tissues. Acta Odontol Scand 1958;16:1-36.

23. Shiga H, Kobayashi Y, Katsuyama H, Yokoyama M, Arakawa I. Gender differences in masticatory performance in dutch adults. J Prosthodonti Res 2012;56:166-9.

24. Ishizaki K, Sakurai K, Tazaki M, Inoue T. Response of Merkel cells in the palatal rugae to the continuous mechanical stimulation by palatal plate. Somatosensory Motor Res 2006;23:63-72. 
25. Fleisch L, Austin JC. A histologic study of the response of masticatory and lining mucosa to mechanical loading in the vervet monkey. J Prosthet Dent 1978;39:211-6.
26. Sharma AK, Mirza FD. Palatal mucosa under dentures: A qualitative histologic and histochemical analysis. J Prosthet Dent 1986;56:574-82.

How to cite this article: Akula R, Srinath HP, Maroli $S$, Yarlagadda SKB, Tej DUK and Srinath T. Effect of Dentures on Palatal Rugae: An Investigation. J Forensic Dent Sci 2020;12(1):35-49.

\begin{tabular}{|l|c|}
\hline \multicolumn{2}{|c|}{ Access this article online } \\
\hline \multirow{3}{*}{ Website: } & Quick Response Code \\
www.jfds.org & \\
& \\
&
\end{tabular}

